\title{
Characterisation of the legume SERK-NIK gene superfamily including splice variants: Implications for development and defence
}

\author{
Kim E Nolan, Sergey Kurdyukov, Ray J Rose*
}

\begin{abstract}
Background: SOMATIC EMBRYOGENESIS RECEPTOR-LIKE KINASE (SERK) genes are part of the regulation of diverse signalling events in plants. Current evidence shows SERK proteins function both in developmental and defence signalling pathways, which occur in response to both peptide and steroid ligands. SERKS are generally present as small gene families in plants, with five SERK genes in Arabidopsis. Knowledge gained primarily through work on Arabidopsis SERKs indicates that these proteins probably interact with a wide range of other receptor kinases and form a fundamental part of many essential signalling pathways. The SERK1 gene of the model legume, Medicago truncatula functions in somatic and zygotic embryogenesis, and during many phases of plant development, including nodule and lateral root formation. However, other SERK genes in M. truncatula and other legumes are largely unidentified and their functions unknown.

Results: To aid the understanding of signalling pathways in M. truncatula, we have identified and annotated the SERK genes in this species. Using degenerate PCR and database mining, eight more SERK-like genes have been identified and these have been shown to be expressed. The amplification and sequencing of several different PCR products from one of these genes is consistent with the presence of splice variants. Four of the eight additional genes identified are upregulated in cultured leaf tissue grown on embryogenic medium. The sequence information obtained from M. truncatula was used to identify SERK family genes in the recently sequenced soybean (Glycine max) genome.

Conclusions: A total of nine SERK or SERK-like genes have been identified in M. truncatula and potentially 17 in soybean. Five M. truncatula SERK genes arose from duplication events not evident in soybean and Lotus. The presence of splice variants has not been previously reported in a SERK gene. Upregulation of four newly identified SERK genes (in addition to the previously described MtSERK1) in embryogenic tissue cultures suggests these genes also play a role in the process of somatic embryogenesis. The phylogenetic relationship of members of the SERK gene family to closely related genes, and to development and defence function is discussed.
\end{abstract}

\section{Background}

The plant receptor-like kinases (RLKs) are a large group of signalling proteins in plants, and are a fundamental part of plant signal transduction. In Arabidopsis the RLK family contains more than 600 members, constituting $60 \%$ of kinases, including almost all of the transmembrane kinases [1]. The position of RLKs in the plasma membrane, with an extracellular receptor

\footnotetext{
* Correspondence: Ray.Rose@newcastle.edu.au Australian Research Council Centre of Excellence for Integrative Legume Research, School of Environmental and Life Sciences. The University of Newcastle. University Dr. Callaghan, NSW, 2308, Australia
}

domain and an intracellular kinase domain, makes them well suited to the task of perceiving a signal external to the cell and conducting that signal into the cell in order to elicit a response. In addition to RLKs there are a number of receptor-like proteins (RLPs). These proteins contain an extracellular domain similar to a RLK but lack the intracellular kinase domain [2]. Based on the criteria of extracellular domain structure and kinase domain phylogeny, RLKs are divided into subfamilies [1]. The SOMATIC EMBRYOGENESIS RECEPTORLIKE KINASE (SERK) gene family belong to the leucinerich repeat (LRR) subfamily of RLKs. These RLKs

\section{() Biomed Central}


contain varying numbers of LRRs in their extracellular receptor domain. SERK genes belong to subgroup II (LRRII) and contain five LRR domains [1].

The family has been defined according to several factors. The first is the presence of 11 exons with conserved splicing boundaries and the tendency for each exon to encode a specific protein domain. Secondly the SERK amino acid sequence contains a particular order of domains from $\mathrm{N}$ to C-terminal: Signal peptide (SP), leucine zipper (ZIP), 5 LRRs, a proline-rich domain (SPP), transmembrane, kinase and C-terminal domains. The SPP domain, containing the SPP motif and the Cterminal domain are considered to be the characteristic domains of SERK proteins [3,4]. Although this is largely correct for annotated SERK genes there is some divergence from the set criteria. The Arabidopsis NIK (NSP interacting kinase) genes share many similarities with SERK genes. NIK genes are so named because of their function in signalling during virus infection $[5,6]$. They are described as interacting with the Nuclear Shuttle Protein (NSP) domain of the virus.

The first SERK genes identified were linked to competence of cultured cells to form somatic embryos in carrot (Daucus carota), orchard grass (Dactylis glomerata) and Arabidopsis thaliana species $[3,7,8]$. Since that time SERK gene expression has been associated with somatic embryogenesis (SE) and organogenesis in numerous species [9-19]. In Arabidopsis five SERK genes have been identified [3] (AtSERKs 1-5) and the gene functioning in SE is AtSERK1 (locus At1g71830). As understanding of the roles of the different members of the SERK gene family has increased, it has become apparent that these genes function in diverse signalling pathways with roles from development to defence. The Arabidopsis SERK gene family is subdivided into two subfamilies, generated from an ancestral gene duplication event. The first subfamily consists of AtSERKs 1 and 2 (SERK1/2) and the second subfamily, AtSERKs 3, 4 and 5 (SERK3/ $4 / 5)[3,20,21]$.

AtSERK1 is required in conjunction with AtSERK2 for anther development and male gametophyte maturation, with double mutants lacking a tapetal layer and failing to develop pollen $[22,23]$. AtSERK1 and AtSERK3 (also called BRI1-associated kinase1 (BAK1)) function in brassinosteroid (BR) signal transduction as components of the BR receptor complex, through dimerization with brassinosteroid-insensitive 1 (BRI1) kinase [24-26]. Both AtSERK3 and AtSERK4 (also called BAK1-LIKE 1 (BKK1)) have been linked to programmed cell death, which can function in both developmental and pathogen defence roles [20,27]. What has emerged from studies of Arabidopsis SERK signalling is that these genes have a tendency to be redundant in pairs with different pairs working in different pathways. Therefore single SERK gene mutants show weak or no phenotype as a second SERK gene can complement their function. Different combinations of SERK genes act in different pathways and these combinations vary according to the pathway. For instance, AtSERK1 and 2 can complement each other in anther development, where AtSERK3 is shown not to function [21]. However, AtSERK1 and 3 function together in BR signalling, and AtSERK3 and 4 are redundant in the programmed cell death pathway. So far a function for AtSERK5 is not known.

In defence responses, AtSERK3/BAK1 functions in pathogen-associated molecular pattern (PAMP)-triggered immunity through heterodimerization with the Flagellin sensing 2 (FLS2) receptor kinase in response to binding by the bacterial PAMP, flagellin [28,29]. A rice SERK, OsSERK1, shows activity in both somatic embryogenesis and fungal defence [30]. The concept of a receptor functioning in both development and pathogen response pathways is reminiscent of the TOLL receptor of Drosophila, also an LRR protein, which is a controlling factor in both embryo development and immunity [28]. Similarly ERECTA in Arabidopsis functions in inflorescence and fruit development as well as pathogen resistance [31].

The ability of AtSERKs to be essential to a number of diverse pathways, receptive to both peptide and steroid ligands, poses the question as to how these similar proteins can show such diversity of function. One possibility is that they are not the primary ligand-binding receptor protein, but instead dimerize with other RLK proteins that are specifically targeted to the one response pathway; for example, the BRI1 RLK in the case of BR signalling, or the FLS2 RLK in immune response to bacterial infection [32]. There is also evidence that AtSERK proteins may function in the process of endocytosis of the active receptor complex following ligand binding $[28,33,34]$.

In the model legume $M$. truncatula we have studied MtSERK1 in relation to SE and other aspects of development $[9,35]$ but no additional information is available in legumes on other members of the SERK family. Legume species comprise some of the world's essential crops for both human and animal nutrition, as a source of biofuels and are of ecological importance due to their ability to form symbiotic relationships with Rhizobium species and fix atmospheric nitrogen [36]. In this study we have identified members of the SERK family in $M$. truncatula and soybean (Glycine max) and analysed their phylogeny in relation to development and defence. In the case of MtSERK3 a number of transcripts have been identified by PCR, consistent with the presence of splice variants, and this is discussed in relation to MtSERK3 function. 


\section{Results}

\section{SERK genes identified in M. truncatula}

Using degenerate PCR from various tissues and database mining we identified eight putative SERK genes in $M$. truncatula, in addition to the already characterized MtSERK1 (Table 1). Degenerate PCR did not detect any $S E R K$-like sequences that were not also found using database searches. Based on our analysis these genes were named MtSERK 2-6 and MtSERK-like 1-3 (MtSERKL 1-3). Five of the genes had one or two corresponding tentative consensus (TC) or EST sequences on the DFCI Medicago gene index (http://compbio.dfci.harvard.edu/tgi/cgi-bin/tgi/gimain.pl?gudb=medicago; shown in Table 1) but none of these represented full length coding sequences. The remaining three genes
(MtSERK3, MtSERK4 and MtSERK6) matched genomic DNA sequences but had no corresponding ESTs. Of the eight predicted genes, five (MtSERKs 2-6) occur in tandem over a $33 \mathrm{~Kb}$ region on chromosome 2 (genomic sequence from GenBank accession numbers AC195567 and AC187356). The other three occur on chromosomes 3,5 and 8 (genomic sequences from GenBank accession numbers CT967306, CT025841 and AC126784 repectively; Table 1). PCR amplification of cDNA from various tissues and sequencing were used to obtain the full length coding sequence of each of the eight identified genes. For one of these genes, seven different cDNA sequences were amplified using nested PCR and sequenced. The presence of these different sequences is consistent with the presence of splice variants. Blastp

Table 1 SERK and SERKL genes identified in M. truncatula

\begin{tabular}{|c|c|c|c|c|c|c|c|c|c|c|c|c|c|c|}
\hline $\begin{array}{l}\text { Gene } \\
\text { name }\end{array}$ & $\begin{array}{l}\text { Genomic } \\
\text { identifier }\end{array}$ & Chr & $\begin{array}{c}\text { TC/EST } \\
\text { identified }\end{array}$ & $\begin{array}{c}\text { Current } \\
\text { TC } \\
\text { number }\end{array}$ & $\begin{array}{l}\text { No of } \\
\text { ESTs on } \\
\text { DFCI }\end{array}$ & $\begin{array}{l}\text { Deg } \\
\text { PCR }\end{array}$ & $\begin{array}{l}\text { Matching } \\
\text { probeset ID } \\
\text { on MtGI }\end{array}$ & $\begin{array}{l}\text { Chr } \\
\text { Pos } \\
\text { (Kbp) }\end{array}$ & $\begin{array}{l}\text { Gene } \\
\text { loci } \\
\text { (Medtr-) }\end{array}$ & SV & $\begin{array}{l}\text { GenBank } \\
\text { Number }\end{array}$ & $\begin{array}{l}\text { Protein } \\
\text { length }\end{array}$ & MW & $\mathrm{pl}$ \\
\hline MtSERK1 & AY162177 & 0 & & TC142011 & 10 & yes & $\begin{array}{l}\text { Mtr.43625.1. } \\
\text { S1_at }\end{array}$ & & & & AY162176 & 627 & 69140.3 & 5.48 \\
\hline MtSERK2 & $\begin{array}{l}\text { AC195567 } \\
\text { AC187356 }\end{array}$ & 2 & $\begin{array}{l}\text { TC100619 } \\
\text { TC97176 }\end{array}$ & TC150247 & 5 & yes & $\begin{array}{l}\text { Mtr.37421.1. } \\
\text { S1_at }\end{array}$ & $\begin{array}{l}1603.3- \\
1609.6\end{array}$ & $\begin{array}{l}2 g 008470 \\
2 g 008480\end{array}$ & & HM640001 & 619 & 68538.8 & 5.47 \\
\hline \multirow[t]{7}{*}{ MtSERK3 } & $\begin{array}{l}\text { AC195567 } \\
\text { AC187356 }\end{array}$ & 2 & & & 0 & no & none present & $\begin{array}{l}1610.0- \\
1616.1\end{array}$ & $\begin{array}{l}2 g 008490 \\
2 g 008500\end{array}$ & SV1 & HM640008 & 586 & 65127.2 & 5.12 \\
\hline & & & & & & & & & & $\mathrm{SV} 2$ & HM769882 & 271 & 29246.0 & 4.98 \\
\hline & & & & & & & & & & SV3 & HM769883 & 562 & 62537.2 & 5.20 \\
\hline & & & & & & & & & & SV4 & HM769884 & 247 & 26656.1 & 5.22 \\
\hline & & & & & & & & & & SV5 & HM769885 & 154 & 16964.2 & 4.59 \\
\hline & & & & & & & & & & SV6 & HM769886 & 154 & 16964.2 & 4.59 \\
\hline & & & & & & & & & & SV7 & HM769887 & 154 & 16964.2 & 4.59 \\
\hline MtSERK4 & $\begin{array}{l}\text { AC } 195567 \\
\text { AC } 187356\end{array}$ & 2 & & & 0 & no & none present & $\begin{array}{l}1615.7- \\
1621.4\end{array}$ & $2 \mathrm{~g} 008510$ & & HM640002 & 615 & 67882.3 & 5.50 \\
\hline MtSERK5 & AC195567 & 2 & $\begin{array}{l}\text { TC104947 } \\
\text { TC110830 }\end{array}$ & $\begin{array}{l}\text { TC155497 } \\
\text { TC151948 }\end{array}$ & 8 & yes & $\begin{array}{l}\text { Mtr.39468.1. } \\
\text { S1_at } \\
\text { Mtr.11713.1. } \\
\text { S1_at }\end{array}$ & $\begin{array}{l}1622.7- \\
1628.9\end{array}$ & $2 g 008520$ & & HM640003 & 620 & 68615.9 & 5.61 \\
\hline MtSERK6 & AC195567 & 2 & & & 0 & no & none present & $\begin{array}{l}1629.2- \\
1636.2\end{array}$ & $\begin{array}{l}2 \mathrm{~g} 008530 \\
2 \mathrm{~g} 008540\end{array}$ & & HM640004 & 642 & 70720.3 & 5.41 \\
\hline MtSERKL1 & AC126784 & 8 & CB891120 & TC143055 & 4 & no & $\begin{array}{l}\text { Mtr.15874.1. } \\
\text { S1_s_at } \\
\text { Mtr.15874.1. } \\
\text { S1_at }\end{array}$ & $\begin{array}{l}35000.0- \\
35005.0\end{array}$ & $8 g 144660$ & & HM640005 & 640 & 70293.2 & 6.66 \\
\hline MtSERKL2 & CT025841 & 5 & TC109616 & TC150718 & 5 & no & $\begin{array}{l}\text { Mtr.41552.1. } \\
\text { S1_at }\end{array}$ & $\begin{array}{l}14476.6- \\
14481.4\end{array}$ & $5 g 035120$ & & HM640006 & 625 & 69142.3 & 6.86 \\
\hline MtSERKL3 & СТ967306 & 3 & TC97017 & TC166655 & 10 & no & $\begin{array}{l}\text { Mtr.44258.1. } \\
\text { S1_at }\end{array}$ & $\begin{array}{l}24728.8- \\
24736.2\end{array}$ & $3 g 101870$ & & HM640007 & 609 & 68019.8 & 5.64 \\
\hline
\end{tabular}

Summary of SERK and SERKL genes in M. truncatula including splice variants (SV1-7) of MtSERK3. Gene name refers to the final name given to each gene. The genomic identifier is the GenBank number of the genomic sequence containing each gene. Chr is chromosome number. TC/EST identified refers to any matching TC or EST sequence found on the DFCI Medicago gene index at the time the eight new genes were first identified. These numbers have since been updated and sometimes divided into separate sequences. Current TC number shows the current corresponding TC numbers for each sequence. No. of ESTs on DFCl is the number of ESTs used to compile each TC sequence on the DFCl Medicago gene index. Detected on degenerate PCR indicates which sequences we found using that technique. Matching probeset ID on MtGI indicates the corresponding probeset on the M. truncatula Gene Expression Atlas. Chr Pos is the gene position in kilobase pairs $(\mathrm{Kbp})$ on each chromosome established from CViT blast searches. Gene loci indicates the gene locus number/s present at each site. Splice variant (SV) numbers of the 7 MtSERK3 SVs are given. GenBank numbers apply to full-length mRNA sequences deposited on the NCBI database. Length, molecular weight $(\mathrm{MW})$ and $\mathrm{pl}$ values of predicted protein sequences are shown. 
searches of all of the predicted amino acid sequences of the putative SERK genes on the NCBI database http:// www.ncbi.nlm.nih.gov showed MtSERKs 2-6 have high similarity to AtSERK3. The other three MtSERKL genes are similar to $S E R K S$ from various species, but in Arabidopsis, MtSERKL1 and MtSERKL2 are more similar to NIK genes. The homology of the $M$. truncatula SERK and SERKL sequences with each other and with Arabidopsis SERK and NIK sequences is shown in Additional file 1.

In order to determine the chromosomal position of each gene genomic full-length coding sequences plus several hundred bases 5' and 3' of each gene were used for a CViT blast search of the $M$. truncatula pseudomolecule: MT3.0 database. Each of the Medicago SERK and SERKL genes, except for MtSERK1, showed 100\% match to the database, and the position of these is shown in Table 1. MtSERK1 is not present on this database, with its closest match corresponding to part of MtSERK2 sequence on chromosome 2 . The gene loci numbers are also shown in Table 1, with MtSERKs 2,3 and 5 each occupying two loci.

\section{Predicted motifs in Medicago genes and comparison with Arabidopsis SERKs}

The positions of the different SERK domains in Arabidopsis SERKs are indicated above the sequence alignment in Figure 1. All of the M. truncatula sequences except for MtSERK3 have a predicted signal peptide. MtSERK3 is predicted to be secreted in a non-classical manner. The consensus sequence of a leucine zipper Leu- $\mathrm{X}_{6}$-Leu- $\mathrm{X}_{6}$-Leu- $\mathrm{X}_{6}$-Leu, where $\mathrm{X}$ is any residue [37] is present in MtSERKs 1, 2, 5 and 6. It is absent in the remaining $M$. truncatula SERK-like proteins and is also absent in Arabidopsis SERKs 4 and 5 as well as the three Arabidopsis NIKs. All of these proteins have partial leucine zipper sequences, with the first Leu- $\mathrm{X}_{6}$-Leu sequence intact, but lack other conserved leucines and/ or have extra residues between conserved leucines (Figure 1). The positions of the five SERK LRRs are indicated in Figure 1. There is good alignment of the LRRs with the exception of LRR 5 in the three Medicago SERKL proteins. The SPP domain is not well conserved. The SERK-characteristic SPP motif, highlighted yellow in Figure 1 is not present in all SERK proteins with AtSERKs 4 and 5 lacking this motif. In $M$. truncatula the SPP motif is present in MtSERKs 1, 2, 4 and 5, but is lacking in the other proteins. The Medicago SERKL proteins show the least amount of homology in this domain. All of the M. truncatula sequences contain predicted transmembrane and kinase domains. The genomic structure of each of the $M$. truncatula SERK and SERKL genes and the relative positions of the SERK genes on chromosome 2 are shown in Figure 2. Each of the genes contains 11 exons which is characteristic of SERK genes. The gene encoding several putative splice variants is $M t S E R K 3$. One of the splice variants contains the usual SERK exon structure with eleven exons as shown in Figure 2. The main variation in the gene structure between the different $M$. truncatula genes is in the length of the introns.

Another characteristic of SERK genes is conservation of exon boundary sites with the tendency for different protein domains to be encoded by separate exons [4]. The positions of each exon boundary site in each sequence are shown in Figure 1. Each of the M. truncatula sequences identified and the Arabidopsis NIKs have similar boundary sites to the Arabidopsis SERKs, with the exception of AtNIK1, which is missing two boundary sites, with a single exon encoding the equivalent of exons 9, 10 and 11 in the other genes. The boundaries of greatest divergence occur between exons $6 / 7$ and $7 / 8$. Exons 6, 7 and 8 encode LRR5, the SPP and the transmembrane domains respectively.

\section{SERK gene prediction from the soybean genome}

Soybean (Glycine max) has three genes annotated as SERK genes on the NCBI database. However two of these sequences (GenBank numbers EU869193 and FJ014794) are sequences from the same gene. The other sequence is Genbank number EU888313. There is also one annotated NIK gene in soybean (GenBank number FJ014718). To identify other putative SERK and SERKlike genes in soybean, the mRNA sequences of the $M$. truncatula SERK and SERK-like genes were blasted against the genomic sequence of soybean. Fourteen more SERK-like genomic sequences were obtained, and from these mRNA and amino acid sequences were predicted.

\section{Phylogenetic analysis of legume SERK genes}

A phylogenetic tree was constructed from the predicted amino acid sequences of the M.truncatula SERK and SERK-like genes, the three soybean SERK and NIK genes present in the database and the fourteen soybean genes predicted from the soybean genome sequence. Also included in the tree are all LRRII subgroup RLKLRR genes from Arabidopsis and SERKs from the NCBI database representing full length AA sequences from a number of other plant species (Figure 3). As indicated by the blast searches some of the $M$. truncatula sequences form a clade with the known SERKs. MtSERKL1 and MtSERKL2 fall into a clade with the soybean and Arabidopsis NIKs. Sequences of four of the predicted soybean genes also fall in the NIK clade. One Medicago sequence, MtSERKL3, along with three Arabidopsis sequences and four of the predicted soybean sequences form a clade that is separate from the SERK 


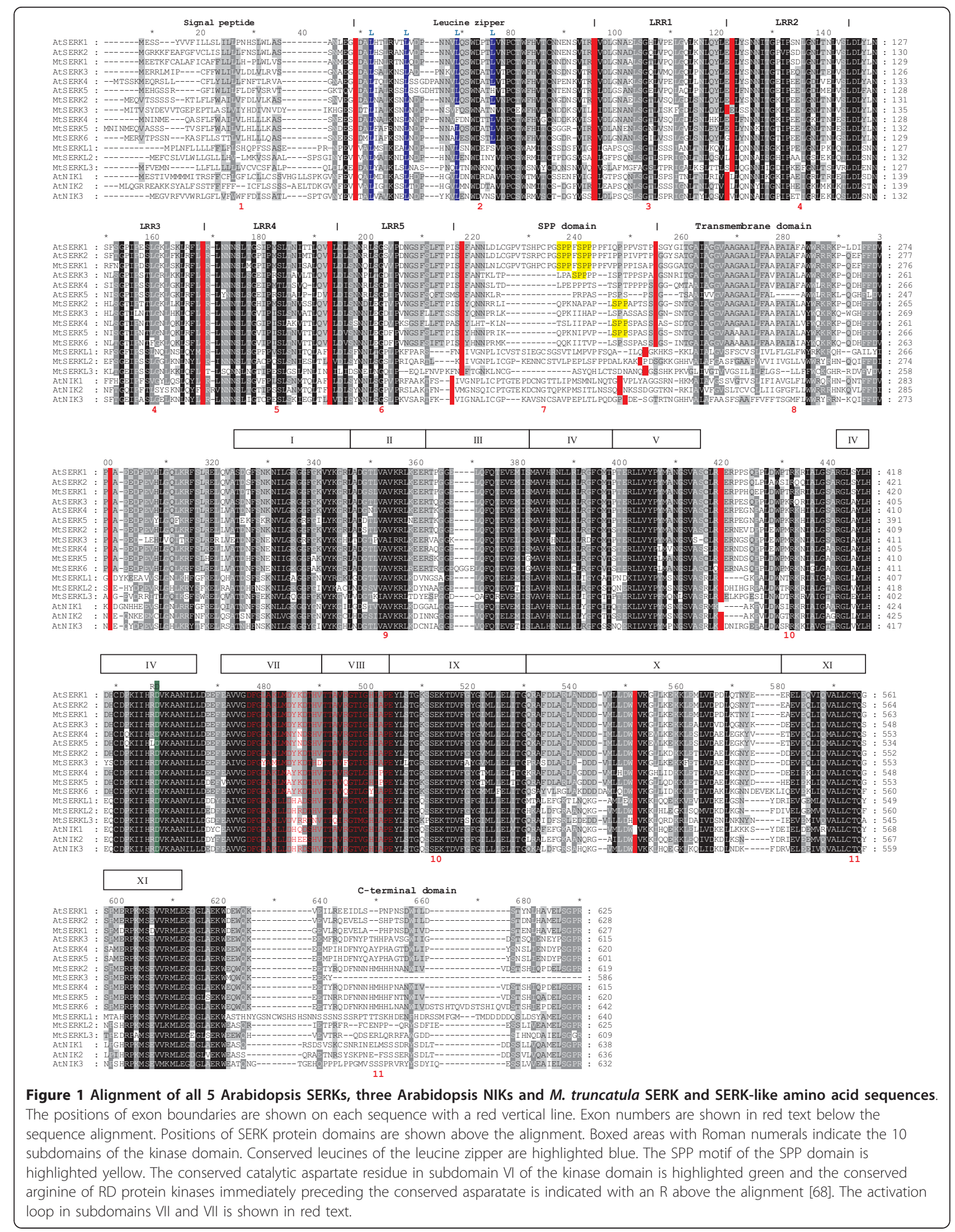




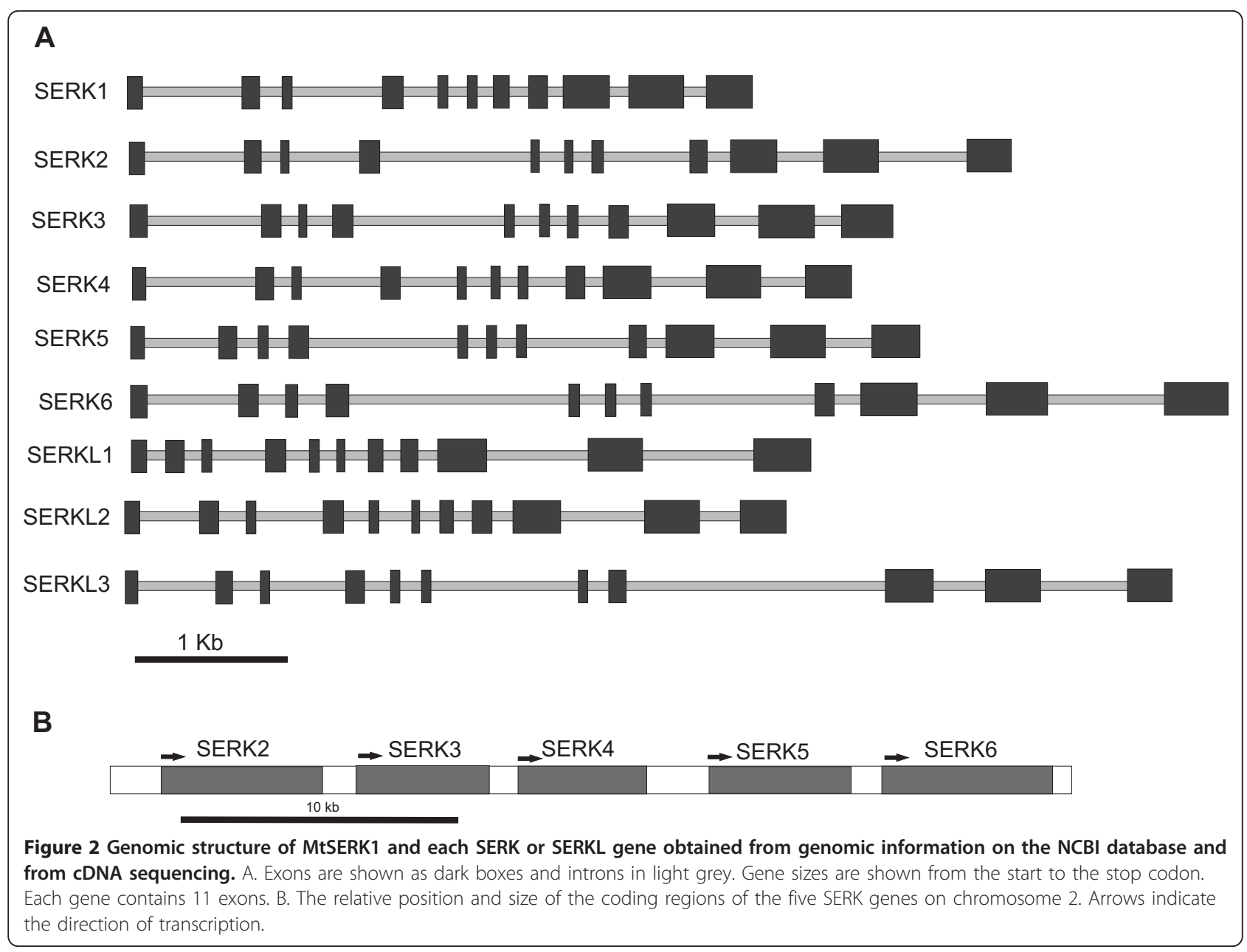

and NIK clades (Labelled "Other" in Figure 3). The four non-Arabidopsis, non-legume sequences that fall in the NIK clade (Pt1, Os1, PpSERK1 and PpSERK2 in Figure 3) have been annotated as SERKs in the literature and/ or on the NCBI database. This phylogenetic analysis shows that the five sequences from chromosome 2 that have been named as MtSERK2-6 are part of the SERK3/ 4/5 family clade, with MtSERK1 the only M. truncatula sequence in the SERK1/2 subfamily. One known and two predicted soybean sequences fall into the SERK1/2 subfamily. One known and four predicted soybean sequences fall into the SERK3/4/5 subfamily. Together the phylogenetic and exon boundary results indicate high similarity between the SERK and NIK genes. The $M$. truncatula sequences have been deposited on the NCBI database (For GenBank numbers see Table 1).

In the SERK3/4/5 subfamily, two soybean genes lie adjacent on chromosome 5, (Glyma05g24770 and Glyma05g24790) but there is not a region with five genes in tandem as is found on chromosome 2 in M. truncatula. Lotus japonicus is more closely related to $M$. truncatula than soybean [38]. A search of the database revealed only one Lotus predicted gene similar to the Medicago SERK3/4/5 genes. This gene occurs on chromosome 6 (Genbank accession number AP006424), which is syntenic to M. truncatula chromosome 2 [39]. This Lotus genomic DNA sequence showed sequence homology with all five Medicago SERK3/4/5 genes, with some sequence homology in introns and in $5^{\prime}$ and $3^{\prime}$ untranslated regions, as well as in exons. These results, combined with the fact that no other potential sequences were found in the Lotus genome, indicate that the single SERK gene region on Lotus chromosome 6 probably corresponds to the five SERK gene region on M. truncatula chromosome 2. These five SERK genes in Medicago may have duplicated since it diverged from Lotus. At this point it is unknown whether legumes closely related to Medicago also have replication of this SERK gene as there is as yet no sequence information. The intron sequences of the five replicated M. truncatula genes were used to estimate the times of duplication of these genes. It is estimated that duplication 


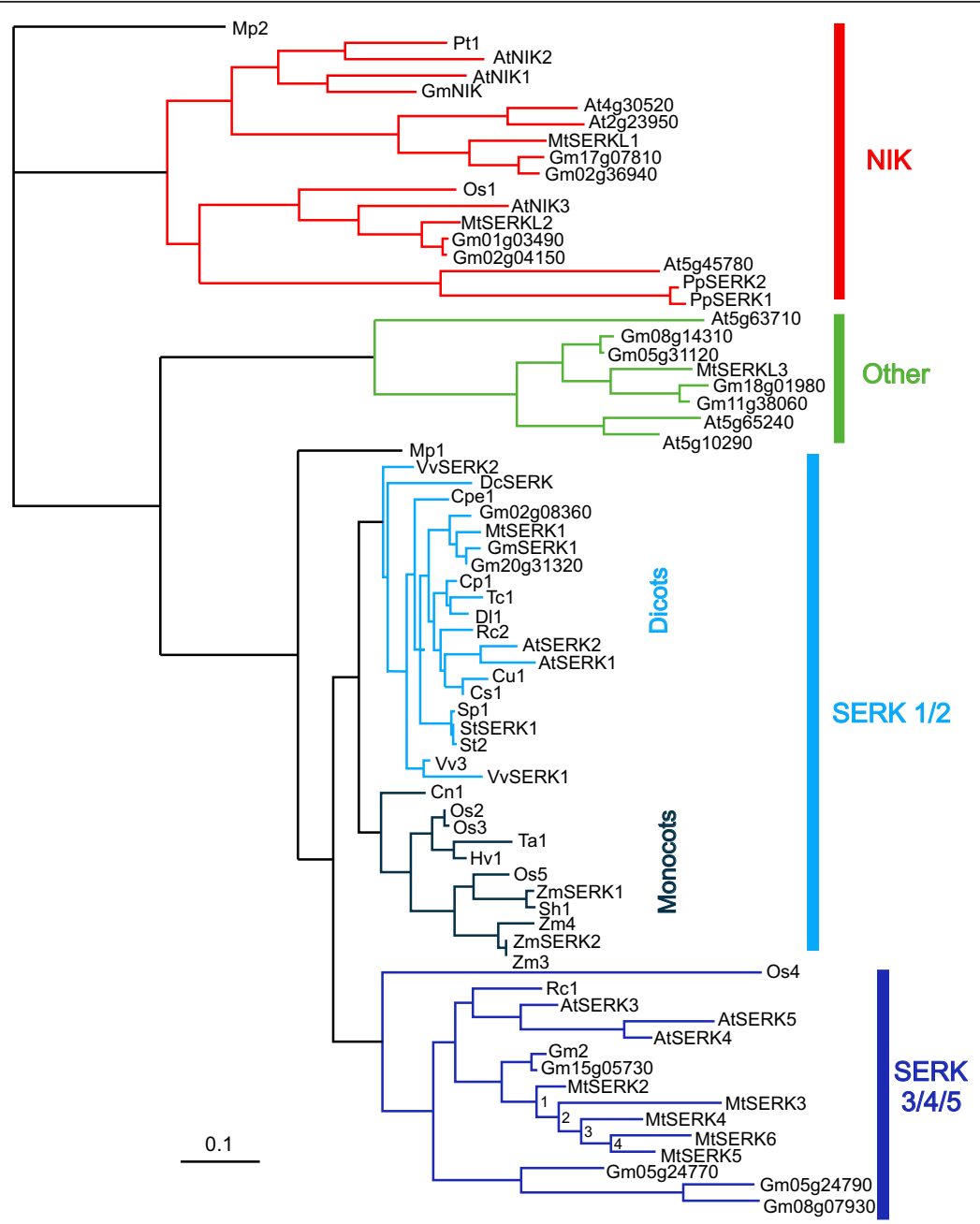

Figure 3 Phlyogenetic analysis of protein sequences from all Arabidopsis RLK-LRR subclass LRRII genes, Medicago SERK and SERKL genes, known and predicted NIK and SERK-like protein sequences from soybean and SERK or SERK-like genes from a number of different species. The soybean sequences that were predicted from genomic sequence are indicated by their gene locus number preceded by "Gm." The loci numbers of soybean protein sequences from the protein database are Gm10g36280 (GmSERK1), Gm08g19270 (Gm2) and Gm13g07060 (GmNIK). Sequences falling into the SERK1/2 subfamily are indicated with blue lines-sequences from dicotyledonous plants in light blue and from monocotyledonous plants in dark blue. The SERK3/4/5 subfamily is indicated with purple lines. Other non-SERK, non-NIK genes are a sister clade to these (shown in green). Sequences belonging to the NIK family clade are indicated with red lines. Sequences from the primitive Bryophyte, Marchantia polymorpha, Mp1 and Mp2, sit separately from the other family genes, but could be classed as a SERK and a NIK gene respectively. Estimated times of duplication events (indicated by numbers 1-4) in M. truncatula SERK 3/4/5 subfamily genes are: 1 - 3.25, 2 3.05, 3 - 2.65 and 4 - 2.2 million years ago. Plant species abbreviations used in tree. At - Arabidopsis thaliana, Cp - Carica papaya (papaya), Cs Citris sinensis (sweet orange), Cu - Citrus unshiu (Satsuma orange), Cn - Cocus nucifera (coconut), Cpe - Cyclamen persicum, Dc - Daucus carota (carrot), DI - Dimocarpus longan (logan), Gm - Glycine max (soybean), Hv - Hordeum vulgare (barley), Mp - Marchantia polymorpha (liverwort), Mt Medicago truncatula (barrel medic), Os - Oryza sativa (rice), Pp - Poa pratensis (Kentucky bluegrass), Pt - Populus tomentose (Chinese white poplar), Rc - Ricinus communis (castor oil plant), Sh - Saccharum hybrid cultivar (sugarcane), Solanum peruvianum (Peruvian nightshade), St - Solanum tuberosum (potato), Tc - Theobroma cacao (cocoa), Ta - Triticum aestivum (bread wheat), Vv - Vitis Vinifera (grape), Zm - Zea mays (maize). Locus number or sequence identifier for the sequences shown are: AtSERK1 - At1G71830, AtSERK2 - At1G34210, AtSERK3 - At4G33430, AtSERK4 At2g13790, AtSERK5 - At2G13800, AtNIK1 - At5g16000, AtNIK2 - At3g25560, AtNIK3 - At1G60800, Cp1 - ABS32233.1, Cs1 - ACP20180.1, Cu1 BAD32780.1, Cn1 - AAV58833.2, Cpe1 - ABS11235, DCSERK - AAB61708.1, Dl1 - ACH87659.2, GmSERK1 - ACJ64717.1, Gm2 - ACJ37402.1, GmNIK ACM89473.1, Hv1 - ABN05373.1, Mp1 - BAF79935.1, Mp2 - BAF79962.1, MtSERK1 - AAN64293.1, other M. truncatula genes - see Table 1, Os1 Os01g0171000, Os2 - Os08g0174700, Os3 - Os08g07760, Os4 - Os06g0225300, Os5 - Os04g0457800, PpSERK1 - CAH56437.1, PpSERK2 CAH56436.1, Pt1 - ABG73621.1, Rc1 - XP_002520361.1, Rc2 - XP_002534492.1, Sh1 - ACT22809.1, Sp1 - ABR18800.1, StSERK1 - ABO14173.1, St2 ABO14172.1, TC1 - AAU03482.1, Ta1 - ACD49737.1, VVSERK1 - CAO664642.1, VVSERK2 - CAN65708.1, VV3 - XP_002270847.1, ZmSERK1 NP_001105132.1, ZmSERK2 - NP_001105133.1, Zm3 - ACL53442.1, Zm4 - ACF87700.1 Other Arabidopsis RLK-LRRIl sequences are labelled with their gene locus number. Associated publications: Cu1 (CitSERK1 [12], Cn1 [17], DcSERK [7], Mp1 (MpRLK2) and Mp2 (MpRLK29 [40], MtSERK1 [9], Os2 (OsSERK1 [69,70], Os3 (OsBISERK1 [43], Os4 (OsSERK3 [70], Os5 (OsSERK1 [30] and OsSERK2 [70], PpSERK1, PpSERK2 [44], StSERK1 [15], Tc1 [71], VVSERK1 and VVSERK2 [14], ZmSERK1 and ZmSERK2 [4]. 
events occurred at 3.25, 3.05, 2.65 and 2.2 million years ago as indicated in Figure 3.

\section{MtSERK3 transcripts}

PCR analysis suggested a total of seven different transcripts consistent with seven splice variants of MtSERK3 . The differences observed between the splice variants is that they either include an intron or introns in their sequence and/or are missing exon 3 (Figure 4). Introns that are included as exons are introns 5, 6 and 8, either alone or in combination. Each of these intron sequences introduces a stop codon thereby creating a truncated coding sequence. Splice variant (SV) 1 has the structure of a normal SERK gene, containing 11 exons. SV3 is also full length except it lacks exon 3, which encodes the first LRR. SV2 and SV4 retain intron 8, with SV4 also lacking exon 3 . The remaining three splice variants lack exon 3 and retain intron 5 and its associated stop codon. SV5 and SV6 retain intron/s after intron 5, but the three SVs 5-7 encode the same protein sequence. Together the seven SVs encode five predicted proteins. Although five of the SV sequences contain stop codons in introns 5 or 8 , the transcript continues through the remaining coding sections found in a typical SERK gene. In these sequences a second possible transcript occurs with a predicted start codon in exon 9 in the region encoding subdomain IV of the the kinase domain. This sequence continues through to the position of the stop codon in exon 11 of SV1 (usual SERK gene structure). This was confirmed by sequencing in SVs 4, 5, 6 and 7 . In SV2, sequence data was not obtained for sequence corresponding to most of exon 10 and exon 11.

Although the MtSERK3 gene contains the typical 11 exon SERK genomic structure and SV1 has characteristics of a typical SERK transcript, there are some features that distinguish this gene from other SERKs. The first feature is

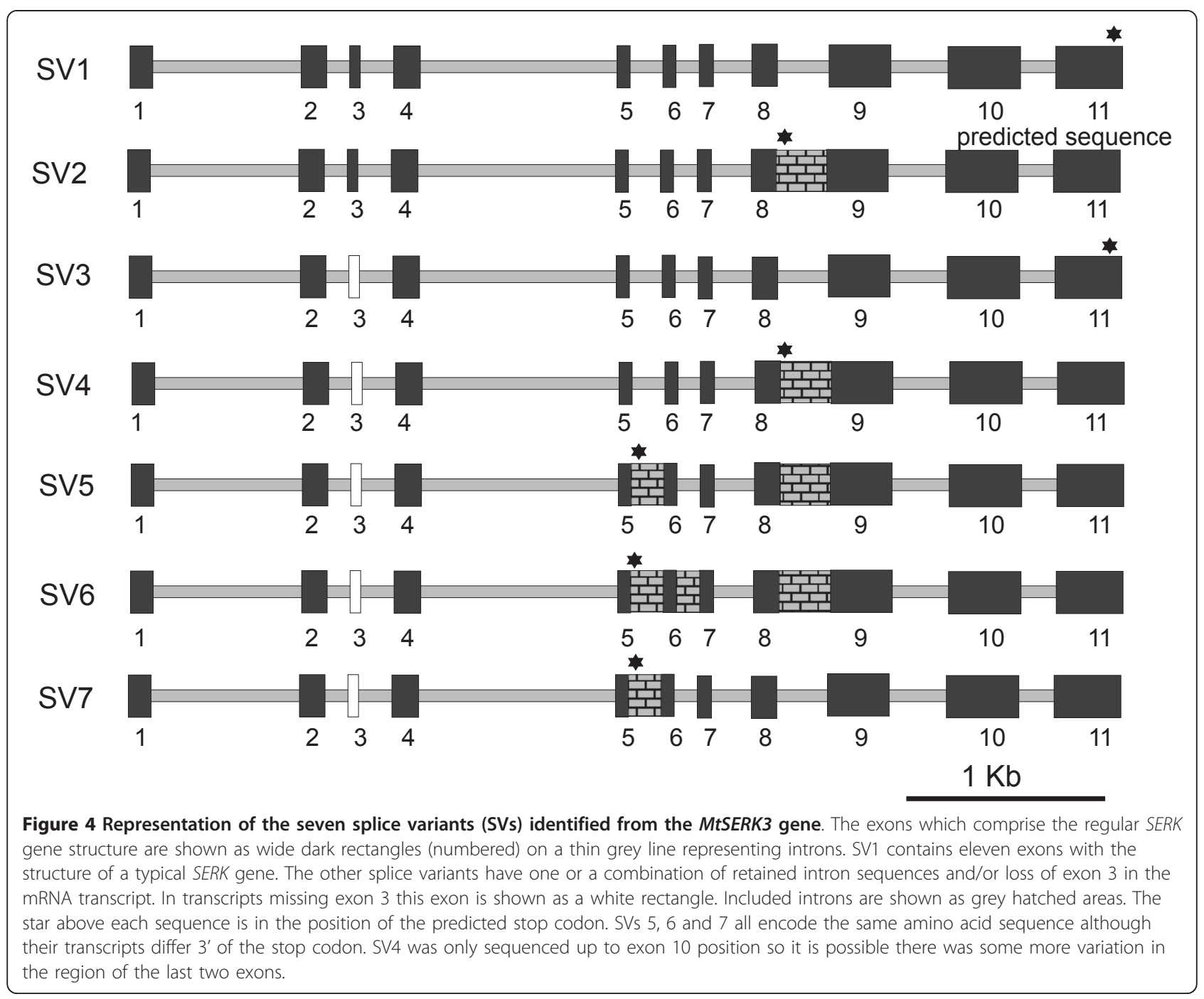


the absence of a predicted signal peptide and the second is a truncated C-terminal domain, with the coding sequence terminating just after the kinase domain (Figure 1).

\section{Expression of Medicago SERKs during the induction of somatic embryogenesis in culture}

The apparent recent duplications of an ancestral gene to create the five SERK genes on chromosome 2 raised the question of whether or not the five Medicago genes are redundant in function of whether they have developed divergent functions. Our previous work showed that $M T S E R K 1$ expression is induced in somatic embryoforming and root forming cultures [9] and we were interested to know if other SERK genes played a role in SE. Quantitiative RT-PCR (qPCR) expression studies were conducted on these five MtSERKs in cultured $M$. truncatula tissue. Relative expression was compared over a four-week time course in cultured leaf tissue from both the embryogenic 2HA seedline and the nonembryogenic Jemalong seedline (Figure 5). The expression of $M t S E R K 3$ was measured using primers that would amplify all putative splice variants of this gene. Therefore expression shown is the sum expression of all splice variants. Like MtSERK1, MtSERKs 3-6 are upregulated within the first week of culture and show similar expression in both the embryogenic 2HA and nonembryogenic Jemalong genotypes. These results show that MtSERK1 is not the only SERK gene induced in culture at the time of induction of SE. MtSERKs 3 and 5 are upregulated four to five-fold over expression in the starting leaf material and remain relatively high over the four weeks. This is a similar expression pattern to that observed for MtSERK1 [9]. However, as the expression results for $M t S E R K 3$ do not distinguish between splice variants, it is not known which or how many splice variants contribute to these expression levels. Expression of $M T S E R K 4$ and 6 are more significantly upregulated (1220 fold) within the first week of culture, then the expression decreases slightly (but not significantly) over the culture time measured. The variation in expression pattern between $M t S E R K 2$ and the other replicated $S E R K$ genes indicate some differences in function.

\section{Discussion}

SERK genes identified in $M$. truncatula

Previous Southern analysis indicated there are probably five $S E R K$ genes in $M$. truncatula [9], but we have now identified a total of eight SERK or SERKL genes in addition to the previously characterised MtSERK1. Each of these nine genes contains 11 exons which is
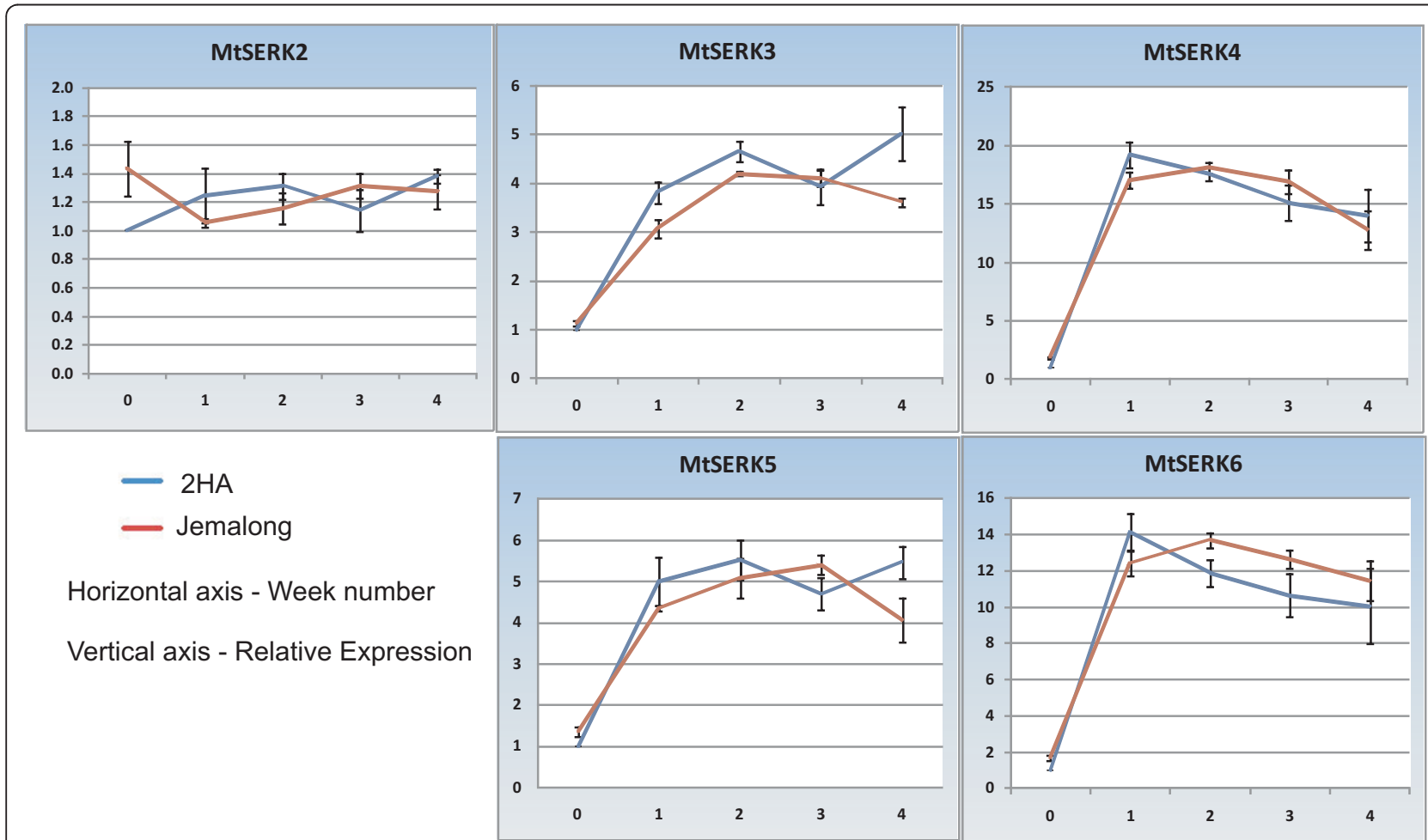

Figure 5 Quantitiative RT-PCR (qPCR) expression studies of MtSERKs 2, 3,4, 5 and 6 in 2HA and Jemalong leaf tissue cultures over a four week culture period. Results shown are means \pm standard error of 3 biological repeats, calibrated to expression in the starting leaf tissue (week 0). 
characteristic of SERK genes, as well as the tendency for each exon to encode a specific protein domain. Phylogenetic analysis shows that five of these genes are SERKs, belonging to the SERK 3/4/5 subfamily. The other three do not fall into the SERK family as defined in Arabidopsis, but rather are $S E R K$-like genes. Two of them, MtSERKL1 and MtSERKL2 fall into the NIK family, which is highly similar to the SERK family. The third one, MtSERKL3 is also closely related but is not in the same clade as the SERK or NIK genes.

The carrot SERK does not contain a signal peptide, but rather starts from the leucine zipper (exon 2 in other SERKs). A perfect leucine zipper (Leu- $\mathrm{X}_{6}$-Leu- $\mathrm{X}_{6}$ Leu- $\mathrm{X}_{6}$-Leu [37]), is not present in AtSERKs 4 and 5 and the specific SPP motif of the SPP domain is also lacking in these sequences (Figure 1). However, phylogenetic analysis favours the view that these are still SERKs [40](Figure 3). The Arabidopsis NIK genes share many similarities with SERK genes. Several genes from other species that have been named as SERK genes fall in the same clade as the NIK genes (Figure 3). Function has not been identified for the three Arabidopsis genes that fall into the clade with MtSERKL3.

\section{SERK genes in legumes}

Although the M. truncatula genome is not yet fully sequenced, we have attempted to identify all SERK genes in this species. From the identified SERKs, only one belongs to the SERK $1 / 2$ subfamily (as defined in Arabidopsis), while there are five in the SERK 3/4/5 subfamily. This indicates there are probably not direct orthologues to the five Arabidopsis SERKs. Recently soybean became the first legume genome to be completely sequenced [41]. The soybean genome has 20 pairs of chromosomes and is a tetraploid, whereas the diploid $M$. truncatula genome has 8 pairs of chromosomes. It is estimated that the soybean genome underwent duplication around 13 million years ago and that any given region in the $M$. truncatula genome is likely to correspond to two regions in the soybean genome [42]. A search for candidate SERK and SERK-like known and predicted genes in soybean revealed 17 genes. Phylogenetic analysis showed that three of these fall into the SERK1/2 subfamily, in comparison to one in M. truncatula. Like Medicago, there are five putative SERK 3/4/5 subfamily members in soybean. Five members fall into the NIK clade and four are part of the clade, containing MtSERKL3, separate to SERK and NIK.

In evolutionary terms, the closest legume to $M$. truncatula that has SERK sequence information is Lotus. The divergence of Medicago and Lotus is estimated to have occurred around 50 million years ago, after the divergence of soybean from Medicago and Lotus around 54 million years ago [38]. The predicted gene in Lotus which appears to be orthologous to the five SERK3/4/5 family member genes is a single copy gene, indicating that the Medicago genes may have duplicated after the divergence of Medicago and Lotus. We estimate the duplication of the Medicago genes occurred much more recently - from 3.25 to 2.2 million years ago. Phylogenetically there are two soybean genes that are equally closely related to these five Medicago SERKs (Gm08g19270 (Gm2) and Gm15g05730; Figure 3). These genes occur on different chromosomes and would originate from duplication of the entire soybean genome rather that duplication of a single gene. However, duplication has occurred on a less closely related soybean SERK3/4/5 gene, with two genes occurring in tandem on chromosome 5 (Gm05g24770 and Gm05g24790; Figure 3). It appears that soybean had its own SERK3/4/5 family member duplication event after its divergence from Medicago and Lotus.

In the SERK and SERKL genes there is not a simple ratio of two soybean genes for every Medicago gene, as would be expected from simple duplication of the soybean genome. It may be that not all of the Medicago genes have been identified, especially those that are not in the SERK clade. On the other hand, there is the likelihood of genome changes in both of the species during the past 50 million years to produce the gene compliment that is identified. Full sequencing of the $M$. truncatula genome would be the only way to fully and conclusively elucidate the complement of these genes in M. truncatula.

\section{SERK and SERKL genes in relation to development and defence}

We propose the similarities between SERK and NIK genes in both structure and function indicate that these gene families, as well as other closely related LRR-RLKs, form part of a larger gene superfamily that operates in signalling during plant development and defence. The families cannot be segregated based on developmental or defence function, with both families containing members in each type of role and some individual members operating in both pathways. For example, Os5 (Figure 3, SERK1/2 subfamily) has a dual role in somatic embryogenesis and defence against fungal pathogens [30], Os3 (Figure 3, SERK1/2 sub-family) is linked to fungal defense [43], socalled PpSERK1 and PpSERK2 (Figure 3, NIK family), act in the early defining stages of apomixis [44]. Therefore it may be advantageous to consider the wider SERK/NIK gene superfamily, encompassing all LRRII subclass genes, when looking at SERK gene function in plants.

\section{Expression of Medicago SERKs during the induction of somatic embryogenesis in culture}

Historically legumes have been difficult to transform and regenerate. The model legume, M. truncatula can 
be transformed and regenerated via somatic embryogenesis, but there is first a requirement for selection of an amenable genotype using tissue culture [45-48]. A role for MtSERK1 during the establishment of embryogenic and organogenic cultures in M. truncatula was implied when it was shown that this gene is upregulated under these culture conditions. Expression of MtSERKs 3, 4, 5 and 6 , like $M t S E R K 1$ is significantly upregulated in both $2 \mathrm{HA}$ and Jemalong cultured tissue in comparison to expression in the starting leaf tissue (week 0), whereas the expression of MtSERK2 remains constant throughout culture and in the starting leaf tissue. This variance in expression pattern suggests that MtSERK2 at least, functions differently to MtSERKs 3-6. MtSERK4 and MtSERK6 are the most highly upregulated SERKS in culture with both showing greater than 12 fold upregulation of expression in the first week of culture (Figure 5). The expression of the three Medicago SERKL genes stayed fairly constant in leaf tissue and in culture suggesting these genes are not part of the regulation of events in culture (data not shown).

Our intron analysis indicates that the MtSERK2 and $M t S E R K 3$ genes arose from the first duplication event, esimated to be 3.25 mya. This raises the possibility that any function dependent on upregulation of MtSERKs 3 6 in culture evolved after the first duplication event which may be of significance when comparing the embryogenic capacity of different legume species. It was also noted that the promoter sequences of the five replicated M. truncatula SERK 3/4/5 subfamily member genes show greater sequence divergence between the members than the intron sequences (data not shown). Such a rapid change in gene promoters also supports the theory of functional divergence of these genes. In $M$. truncatula SERK1 expression is associated with developmental change [35]. It seems likely that as in Arabidopsis, heterodimers involving SERK1 with other SERKs or other RLKs help to regulate legume development.

\section{Splice variant}

To our knowledge, the detection of sequences consistent with the existence of splice variants of MtSERK3 is a novel observation for a SERK gene. An understanding of AS in plants is in its early days, but it is estimated that AS occurs in about $20 \%$ of plant genes. What is known is the predominant form of AS in plants is in the form of intron retention comprising around $50 \%-60 \%$ of AS events, with exon skipping comprising around $8 \%$. This is quite different from the situation in humans where exon skipping is the predominant form of AS (58\%) and intron retention comprises around 5\% [49,50]. Using sequence data from ESTs an attempt has been made to identify alternatively spliced genes in Arabidopsis, rice and legumes and this information has been deposited on the ASIP (Alternative Splicing in Plants) database at http://www.plantgdb.org/ASIP/ [49,50]. As MtSERK3 is one of the genes that had no corresponding ESTs on the database, it is not listed in the M. truncatula splice variants on the ASIP database. None of the five Arabidopsis SERK genes are listed as having splice variants. However, AS events are recorded in other LRR-RLKs, and in a separate study 34 alternatively spliced LRRRLKs were identified in Arabidopsis [51]. AS producing premature stop codons, such as SVs 2,4,5,6 and 7 of $M t S E R K 3$, may produce transcripts that are targets for non-sense mediated RNA decay [49]. However, NerGaon (2004) [52] presented evidence that transcripts with retained introns are exported from the nucleus and are associated with ribosomal complexes thus supporting the view that they may be functional.

The seven splice variant sequences observed in $M t S E R K 3$ are predicted to code for five different proteins (Figure 4), including SV1 that has a regular SERK-like structure. The structure of SV2 and SV4 gives these proteins structural similarity to the known RLPs such as CLAVATA2 (CLV2) [53]. The SVs 5, 6 and 7, encode a single severely truncated predicted protein which contains the N-terminal, lacking LRR1, with a stop codon introduced immediately after the position of LRR4 in a normal SERK gene. This leaves the first two exons, encoding the putative SP and ZIP domains, then three LRRs followed by a stop codon. We have no knowledge of reports of a similar truncated LRR-RLK in the literature and it is quite conceivable that such a protein is targeted for degradation. On the other hand there are other defence proteins that are encoded by alternatively spliced genes where it has been shown that AS of these genes is necessary to enable the defence function [54]. For example, the Arabidopsis RESISTANCE TO PSEUDOMONAS SYRINGAE4 (RPS4) gene belonging to the Toll/interleukin-1 receptor (TIR)-nucleotide binding site (NBS)-Leurich repeat (LRR) class of disease resistance $(R)$ genes is alternatively spliced to give both full-length and truncated proteins, and the presence of all of these proteins is required for disease resistance [55]. In general there is a bias for alternatively spliced genes with intron retention in plants to function in defence and external/internal stimuli-related functions [52]. Additionally, in the mouse, members of the TOLL-like receptor signalling pathway show widespread alternative splicing, which is thought to allow a higher level of diversity in the inflammatory pathway in response to pathogens [56]. The already established role for SERK genes in defence raises the possibility that some defence effect related to AS could be operating in MtSERK3. Of course such a role would need to be shown experimentally.

In keeping with a potential defence role, a recent study suggests that plant LRR-RLK genes can be grouped 
according to whether or not they have undergone gene expansion [57]. The authors propose that the expanded group share similarities with the NBS-LRR resistance genes in their genetic variation and evolution and are more likely to function in disease resistance, whereas the non-expanded group have a tendency to function in growth and development. The expansion of the five Medicago SERK3/4/5 family member genes from a single ancestor may imply a role in defence for one or more of them. This observation along with the similar gene splicing to that observed in TIR-NBS-LRR genes is supportive of a role for MtSERK3 in defence. The rice SERK1/2 family member gene, OsBISERK1, [43] (Os3 in Figure 3) is one example of a defence related gene belonging to the expanded group [57].

MtSERK3 has other unusual features. One is its lack of a predicted signal peptide, although it is predicted to be secreted in a non-classical manner. The other is the truncation of the C-terminal domain in comparison to other SERK proteins. The actual function of the SERK Cterminal domain is unknown, but one possibility is a role in protein-protein interactions [7]. The distinct characteristics of MtSERK3 may indicate a rapid evolution of different function after the gene duplication events which had created five genes from a single ancestral gene. The creation of extra gene copies relaxed selective pressure allowing some copies to evolve new functions, while at least one of the genes maintained the original function. However MtSERK3 is still upregulated in tissue culture which also implies a developmental role during early culture events similar to that of MtSERK1 and to other SERKs that were first described in relation to SE.

\section{Conclusions}

In this study we have identified and sequenced the mRNAs of five more SERK and three SERK-like genes in $M$. truncatula, and used these sequences to identify homologous genes in soybean. Phylogenetic analysis shows that some of these genes fall distinctly in the SERK family, while others are SERK-like which include NIK genes and other LRRII subgroup RLK-LRR family members. The $M$. truncatula SERK3/4/5 subfamily genes have undergone a gene duplication event that is not present in orthologous genes in soybean or Lotus. One of these duplicated genes apparently encodes a number of sequences, consistent with the existence of splice variants, which is a novel finding for a SERK gene. The gene duplication event and the presence of splice variants may be indicative of a role in defence, similar to that observed in NBS-LRR genes. Other members of this replicated SERK3/4/5 gene cluster are upregulated in embryogenic tissue cultures implying a similar developmental role to that previously observed for MtSERK1 [9,35].

\section{Methods}

\section{Degenerate PCR and database mining}

Degenerate primers for PCR were designed in the conserved kinase domain of SERK genes. To give greater specificity at the 3 ' end of the primers, each primer was made into two separate primers with a specific nucleotide at a point of degeneracy close to the 3' end where there was a choice of 2 nucleotides (underlined bases in primer sequences below). This gave the forward primers 8 specific bases and the reverse primer 5 specific bases at the 3' ends. The primers used were Forward 1 - 5'CAR TTY CAR CAN GAR GTN GAA ATG AT-3,' Forward 2 - 5' - CAR TTY CAR CAN GAR GTN GAG ATG AT-3', Reverse 1 5' - CC RTA NCC RAA NA $\bar{C}$ RTC NGT YTT TTC -3', Reverse 2 - 5'- CC RTA NCC RAA NAC RTC NGT YTT CETC -3.' The degeneracy was 256-fold for the forward primers and 1024-fold for the reverse primers, with a predicted amplicon size of around $446 \mathrm{bp}$. Degenerate PCR was performed on cDNA and genomic DNA using a $2 \mu \mathrm{M}$ concentration of each primer. PCR cycling conditions were a denaturation step of $3 \mathrm{~min}$ at $95^{\circ} \mathrm{C}, 40$ cycles of $95^{\circ} \mathrm{C}$ for $30 \mathrm{~s}$, $52^{\circ} \mathrm{C}$ for $30 \mathrm{~s}$ and $72^{\circ} \mathrm{C}$ for $60 \mathrm{~s}$, and then 1 cycle of $72^{\circ} \mathrm{C}$ for $7 \mathrm{~min}$. PCR products were cloned into pGEM Easy vector (Promega) and sequenced. Sequencing of four cDNA clones revealed they all belonged to the same gene which corresponded to TC100619. Sequencing of 14 genomic clones gave four individual sequences, however one of them did not appear to be a SERK sequence. Genes that were detected using degenerate PCR are indicated in Table 1.

To conduct database mining the mRNA sequences of known SERK genes were blasted against $M$. truncatula sequences in the DFCI Medicago Gene Index and NCBI $\mathrm{nr}$ and htgs databases. Two genomic DNA regions containing SERK-like sequences and seven TCs or ESTs were identified in addition to the already annotated MtSERK1. The genomic DNA regions identified were on chromosomes 2 and 5, with the region on chromosome 2 containing multiple predicted SERK-like genes. Four of the detected TCs matched chromosome 2. The remaining three TC/ESTs matched regions on chromosomes 3, 5 and 8. A summary of all sequences is shown in Table 1. All of the SERK and SERK-like sequences identified using degenerate PCR corresponded to sequences identified from the database searches or matched MtSERK1.

The chromosomal location of each M. truncatula SERK and SERKL gene was determined by performing a genomic sequence CViT blast of each gene against the M. truncatula pseudomolecule: MT3.0 database http:// www.medicago.org/genome/cvit_blast.php. The actual gene sequences were obtained from the Medicago GBrowse v3 database http://gbrowse.jcvi.org/cgi-bin/ 
gbrowse/medicago/ by following the links from the CViT blast results, selecting the appropriate postion on the chromosome and downloading the sequence data. These were then compared with the sequence data for each gene obtained from NCBI and from sequencing. Some manual adjustment was required to locate the total gene sequence from some blast results. The corresponding gene loci numbers of each sequence were also obtained from the Medicago GBrowse v3 database. Matching probeset IDs were obtained by blasting mRNA sequences against the Mt Affy Chip Consensus Sequences database on the $M$. truncatula Gene Expression Atlas website http://mtgea.noble.org/v2/.

\section{PCR amplification and sequencing of full length coding regions}

As none of the TC/EST sequences identified represented full length coding sequences, potential coding regions from the individual genomic sequences were predicted using FGENESH software (Softberry; http:// linux1.softberry.com) and this information was matched with sequences obtained from the DFCI Medicago Gene Index. Primers were designed from the known and predicted coding sequences and in predicted $5^{\prime}$ and $3^{\prime}$ untranslated regions, and these were used to amplify full length or overlapping partial length cDNA sequences. These regions were sequenced, either directly from the purified PCR product or were cloned into pGEMeasy vector, electroporated into $E$. coli and sequenced after either miniprep or colony PCR. Using this system any previously unsequenced sections of mRNA transcripts were PCR amplified and sequenced, giving full length sequence data for all of the identified $M$. truncatula genes. The cDNA used to obtain the sequences came from different sources of plant tissue including, flower, leaf, root, seedling, cultured tissue and somatic embryos. Tissue from both $2 \mathrm{HA}$ and Jemalong seedlines was used to make cDNA. Mostly pooled cDNA samples from various tissues were used as a template source. Where possible a full length coding sequence was amplified in a single PCR reaction and used for sequencing. The three genes which did not have any transcript sequences on the database (MtSERKs 3, 4 and 6) required nested PCR reactions or shorter overlapping PCRs to obtain full length product for sequencing. In the case of MtSERK3, numerous nested PCR and cloning reactions from different tissue sources were required to identify the various splice variant sequences. However all of the nested PCR products used for sequencing of splice variants, with the exception of SV2, were full-length or almost full length sequences to ensure the sequence obtained did indeed come from a single transcript. In the case of SV2 the nested reverse primer was in exon 10. In all cases the products of the first PCR reaction, used as a source of template for nested PCR, were created using primers that amplified the full length coding sequence of the gene. Primers used for genes amplified in a single PCR reaction were: MtSERK2 - forward primer 5'-TCT CATCTTTTTGCTTCCATTC-3', reverse primer 5'AAAGTGTTGGTTGCTTGTGTC-3'; MtSERK5 forward primer 5'-GAGAGAGAGGGTTTGTGTTTT-3', reverse primer 5'-AGAGGACGGATTGTGTATTG-3'; MtSER $K L 1$ - forward primer 5'-CTCCTTTACCTTTACCAC ACTTC-3', reverse primer 5'-ATCTACAACAACCCC AAATAACA-3'; MtSERKL2 - forward primer 5'-GGT TTCTTCTGCTGCTCTTTCTC-3', reverse primer 5'CAGAAAGCTCCATTGCTTCTAC-3' and MtSERKL3 forward primer 5'-AATTAAAGGGTTGGTTCATT CTT-3', reverse primer 5'-TCCAATCTGGTATG GT CTGT-3'. MtSERK4 was amplified in two overlapping PCR reactions using the primers - forward primer 5'-GCAAAGAAAACAAACAAAAGCCATAC-3' with reverse primer 5'-CTGGTGACGGTGGAGAAAGTG-3' and forward primer 5'-GAGATGTCCCCAAGAGTG GTTC-3' with reverse primer 5'-TTTATCTCGTTC AGGCAGAGGA-3'. MtSERK6 was amplified using nested PCR reactions. Primers for the first PCR were forward primer 5'-TGGAGTTTGATAATGGGTTT CTTG-3' with reverse primer 5'-CAGGCAGAGGAA GAAGGATTGT-3'. Products from the first PCR were diluted 1 in 100 and amplified using the same reverse primer and a nested forward primer 5'-TTTGG TTC TTCATTTGCTGCTTC-3'. Splice variant sequences for MtSERK3 were obtained using a number of nested PCR reactions followed by cloning and sequencing. For each splice variant the full length coding sequence was amplified in the first PCR reaction. The primers used for the nested PCR amplified a full length or almost full length coding sequence (except for SV2; sequence up to exon 10 obtained). A summary of the tissue and primers used in the PCR reactions to obtain the full SV sequences are given in Additional file 2.

\section{Gene and motif prediction}

The genomic structure of the genes sequenced was determined using Spidey on the NCBI database http://www. ncbi.nlm.nih.gov/IEB/Research/Ostell/Spidey/. Prediction of mRNA sequences from genomic sequences was done using FGENESH software from Softberry http://linux1.softberry.com/berry.phtml. Predicted amino acid sequences from the sequenced genes were used for motif prediction using the ExPASy Proteomics tools server http://au.expasy. org/tools/. A general scan of the sequence was performed using Scan PROCITE [58]. Signal peptides were predicted using SignalP 3.0 [59]. Prediction of whether proteins could be secreted in a non-classical manner (without a signal peptide) was performed using Secretome 2.0 [60]. Due to the lack of plant parameters with this program, the 
protein was classed as mammalian for prediction. Transmembrane domains were predicted using TMHMM 2.0 [61]. MW and pI were estimated using ProtParam [62].

\section{Amino acid sequence alignments and phylogenetic analysis}

Full length predicted amino acid sequences were aligned using ClustalX 2.0.10 [63]. Phylogenetic analysis was performed on aligned sequences using the protein maximum likelihood, proml, programme and tree topology edited using Retree from the PHYLIP (Phylogeny Inference Package) Version 3.69 http://evolution.genetics. washington.edu/phylip.html. Trees were drawn using TreeView 1.6.6 http://www.treeview.net/.

\section{Identification of putative SERK genes in soybean}

A blast search of $\mathrm{Gm}$ genome soybean chromosomes (JGI Glyma1) on the Plant GDB database http://www. plantgdb.org/GmGDB/ was conducted using the mRNA sequences of each of the $M$. truncatula SERK genes to find homologous sequences in the soybean genome. From these searches it was possible to obtain the locus number of each of the matching genes. These loci numbers were used to obtain the corresponding genome and predicted mRNA and AA sequences from the Phytozome database http://www.phytozome.net/, which contains the full sequence of the recently sequenced soybean genome.

\section{Estimation of gene duplication events in MtSERK family members}

To estimate the time of duplication of the MtSERK 3/4/ 5 subfamily member genes, each intron sequence of each gene was compared to the corresponding intron sequence in the other duplicated genes using the Needleman-Wunsch Global Sequence Alignment Tool at NCBI [64]. The following parameters were used for comparison: match cost 2 , mismatch “-3”, gap cost 5 , gap extension 2. In some cases manual adjustment was necessary. The number of substitutions and deletions were counted and the age of duplication (distance) was calculated for each pair, using the assumption of $3 \times 10^{-}$ 10 substitutions/site/year [65], and also taking into account the fact that mutations occur independently in each copy after a duplication event. Comparison of the differences between different pairs of genes allowed the calculation of the sequence and approximate times of duplication events.

\section{Quantitative RT-PCR}

M. truncatula 2HA and Jemalong leaf tissue was collected, sterilised and cultured as described in [9]. RNA was isolated from $2 \mathrm{HA}$ and Jemalong cultured and leaf tissue using the RNAqueous-4PCR kit (Ambion) according to the manufacturer's instructions. All RNA samples were treated with DNase prior to cDNA synthesis. cDNA synthesis was performed using the SuperScript II first-strand synthesis system for RT-PCR (Invitrogen) from $2 \mu \mathrm{g}$ of total RNA using oligo(dT) primers. All qPCR reactions were set up using the CAS1200 robot (Qiagen formerly Corbett) and run on the Rotor-Gene Q (Qiagen formerly Corbett). Primers were designed using Primer3 programme (Primer3 site http://frodo.wi. mit.edu/primer3/). Due to the similarity in sequence between the $M$. truncatula SERK genes, each primer was checked for specificity against an alignment of the other M. truncatula SERK genes. The amplified PCR products were tested for the presence of a single PCR product using a high resolution disassociation curve with temperature increasing in $0.2^{\circ} \mathrm{C}$ increments at the end of each PCR run. For some of the genes a number of different primer sets and annealing temperatures were tested to find conditions with specificity. Primer sequences used were: MtSERK2 - forward primer 5'AGTTGAAGAAAAATGGAACAAGTGA-3', reverse primer 5'- TCAGTGCATCACCTTCAACATTAG-3'; MtSERK3 - forward primer 5'- GTGTATCGTGTTTAC GAGAACGTAATGG-3', reverse primer 5-TCACGGTGAATAATCTTAGGGTCACA-3; MtSERK4 - forward primer 5' - CAATGAAGAAAGTGATGCCCTGAA-3', reverse primer 5'- CATCATTGCATCCAACATGA AACC-3'; MtSERK5 - forward primer 5'- CTTCTT CCAATGATGAAAGTGATGC-3', reverse primer 5'-AT CAACCCGGATTACTCTACCACCAC-3' and MtSERK6 forward primer 5'- CATCACCAGCTTCTTCAGG TAGCA-3', reverse primer 5'- GCAGGAACGTCAAA GAAATGATCC-3'. cDNA was diluted to 1 in 25 for qPCR reactions. Reactions were performed in triplicate in $15 \mu \mathrm{L}$ sample volume using 0.3 units Platinum Taq PCR polymerase (Invitrogen), $1 \times$ Platinum Taq reaction buffer, $3 \mathrm{mM} \mathrm{CaCl}, 0.2 \mathrm{mM}$ each of dATP, dCTP, dGTP, dTTP and $2 \mu \mathrm{M}$ SYTO9 fluorescent dye (Invitrogen). PCR cycling conditions were $94^{\circ} \mathrm{C}$ for $2 \mathrm{~min}$, followed by 40 cycles of $94^{\circ} \mathrm{C}$ for $15 \mathrm{~s}, 60^{\circ} \mathrm{C}$ for $30 \mathrm{~s}$ and $72^{\circ} \mathrm{C}$ for $30 \mathrm{~s}$. For $M t S E R K 3$ and $M t S E R K 6$ PCR reactions the annealing temperature was increased to $64^{\circ} \mathrm{C}$ to increase the specificity of the primers. Gene expression was normalised to expression of GAPDH. GAPDH primers used were forward primer 5'- GACTTT ATTGGTGATACCAGGTCG-3 and reverse primer 5'GGTCAACCACACGGGTACTGTAA-3'. PCR efficiency of each run was calculated using the LinRegPCR programme http://LinRegPCR.nl [66]. Relative expression was calculated according to the method of Pfaffl [67]. Results shown are means \pm SE of three biological repeats. 


\section{Additional material}

Additional file 1: Sequence identity of mRNA sequences (top) and identity and similarity of amino acid sequences (bottom) of the $M$. truncatula SERK and SERKL with each other and with Arabidopsis SERKs and NIKs. Tables are colour coded with darker colour indicating higher similarity.

Additional file 2: Summary of the nested or semi-nested PCR primers used to PCR amplify MtSERK3 splice variant mRNAs for sequencing, and the source tissue used as template for the first PCR reactions.

\section{Acknowledgements}

Funding from ARC Centre of Excellence Grant CEO348212 (RR). We thank Mark Rowland and Sam Zhang for technical assistance.

\section{Authors' contributions}

KN conducted the experimental work, database mining, phylogenetic analysis and drafted the manuscript. SK compared Lotus and Medicago sequences and did the analysis of gene duplication events. RR supervised the analysis, discussed the results and critically revised the manuscript. Al authors have read and approved the final manuscript.

Received: 18 October 2010 Accepted: 9 March 2011

Published: 9 March 2011

\section{References}

1. Shiu S-H, Bleecker AB: Expansion of the Receptor-Like Kinase/Pelle Gene Family and Receptor-Like Proteins in Arabidopsis. Plant Physiol 2003, 132:530-543.

2. Tor M, Lotze MT, Holton N: Receptor-mediated signalling in plants: molecular patterns and programmes. J Exp Bot 2009, 60:3645-3654.

3. Hecht V, Vielle-Calzada JP, Hartog MV, Schmidt EDL, Boutilier K, Grossniklaus U, de Vries SC: The Arabidopsis SOMATIC EMBRYOGENESIS RECEPTOR KINASE 1 gene is expressed in developing ovules and embryos and enhances embryogenic competence in culture. Plant Physiol 2001, 127:803-816.

4. Baudino S, Hansen S, Brettschneider R, Hecht VRG, Dresselhaus T, Lorz H, Dumas C, Rogowsky PM: Molecular characterisation of two novel maize LRR receptor-like kinases, which belong to the SERK gene family. Planta 2001, 213:1-10.

5. Mariano AC, Andrade MO, Santos AA, Carolino SMB, Oliveira ML, BaracatPereira MC, Brommonshenkel SH, Fontes EPB: Identification of a novel receptor-like protein kinase that interacts with a geminivirus nuclear shuttle protein. Virology 2004, 318:24-31.

6. Fontes EPB, Santos AA, Luz DF, Waclawovsky AJ, Chory J: The geminivirus nuclear shuttle protein is a virulence factor that suppresses transmembrane receptor kinase activity. Genes Dev 2004, 18:2545-2556.

7. Schmidt EDL, Guzzo F, Toonen MAJ, de Vries SC: A leucine-rich repeat containing receptor-like kinase marks somatic plant cells competent to form embryos. Development 1997, 124:2049-2062.

8. Somleva MN, Schmidt EDL, de Vries SC: Embryogenic cells in Dactylis glomerata L. (Poaceae) explants identified by cell tracking and by SERK expression. Plant Cell Rep 2000, 19:718-726.

9. Nolan KE, Irwanto RR, Rose RJ: Auxin up-regulates MtSERK1 expression in both Medicago truncatula root-forming and embryogenic cultures. Plant Physiol 2003, 133:218-230.

10. Thomas C, Meyer D, Himber C, Steinmetz A: Spatial expression of a sunflower SERK gene during induction of somatic embryogenesis and shoot organogenesis. Plant Physiol Biochem 2004, 42:35-42.

11. Santa-Catarina C, Hanai LR, Dornelas MC, Viana AM, Floh EIS: SERK gene homolog expression, polyamines and amino acids associated with somatic embryogenic competence of Ocotea catharinensis Mez. (Lauraceae). Plant Cell Tissue Organ Cult 2004, 79:53-61.

12. Shimada T, Hirabayashi T, Endo T, Fujii H, Kita M, Omura M: Isolation and characterization of the somatic embryogenesis receptor-like kinase gene homologue (CitSERK1) from Citrus unshiu Marc. Sci Hortic 2005, 103:233-238.

13. de Oliveira Santos M, Romano E, Yotoko KSC, Tinoco MLP, Dias BBA, Aragao FJL: Characterisation of the cacao somatic embryogenesis receptor-like kinase (SERK) gene expressed during somatic embryogenesis. Plant Sci 2005, 168:723-729.

14. Schellenbaum P, Jacques A, Maillot P, Bertsch C, Mazet F, Farine S, Walter B: Characterization of VvSERK1, VvSERK2, VvSERK3 and VvL1L genes and their expression during somatic embryogenesis of grapevine (Vitis vinifera L.). Plant Cell Rep 2008, 27:1799-1809.

15. Sharma SK, Millam S, Hein I, Bryan GJ: Cloning and molecular characterisation of a potato SERK gene transcriptionally induced during initiation of somatic embryogenesis. Planta 2008, 228:319-330.

16. Singla B, Khurana JP, Khurana P: Characterization of three somatic embryogenesis receptor kinase genes from wheat, Triticum aestivum. Plant Cell Rep 2008, 27:833-843.

17. Perez-Nunez MT, Souza R, Saenz L, Chan JL, Zuniga-Aguilar JJ, Oropeza C: Detection of a SERK-like gene in coconut and analysis of its expression during the formation of embryogenic callus and somatic embryos. Plant Cell Rep 2009, 28:11-19.

18. Huang X, Lu XY, Zhao JT, Chen JK, Dai XM, Xiao W, Chen YP, Chen YF, Huang XL: MaSERK1 gene expression associated with somatic embryogenic competence and disease resistance response in banana (Musa spp.). Plant Mol Biol Rep 2010, 28:309-316.

19. Zakizadeh H, Stummann BM, Lutken H, Muller R: Isolation and characterization of four somatic embryogenesis receptor-like kinase (RhSERK) genes from miniature potted rose (Rosa hybrida cv. Linda). Plant Cell Tissue Organ Cult 2010, 101:331-338.

20. He K, Gou X, Yuan T, Lin H, Asami T, Yoshida S, Russell SD, Li J: BAK1 and BKK1 regulate brassinosteroid-dependent growth and brassinosteroidindependent cell-death pathways. Curr Biol 2007, 17:1109-1115.

21. Albrecht C, Russinova E, Kemmerling B, Kwaaitaal M, de Vries SC: Arabidopsis SOMATIC EMBRYOGENESIS RECEPTOR KINASE proteins serve brassinosteroid-dependent and -independent signaling pathways. Plant Physiol 2008, 148:611-619.

22. Colcombet J, Boisson-Dernier A, Ros-Palau R, Vera CE, Schroeder Il: Arabidopsis SOMATIC EMBRYOGENESIS RECEPTOR KINASES1 and 2 are essential for tapetum development and microspore maturation. Plant Cell 2005, 17:3350-3361.

23. Albrecht C, Russinova E, Hecht V, Baaijens E, de Vries S: The Arabidopsis thaliana SOMATIC EMBRYOGENESIS RECEPTOR-LIKE KINASES1 and 2 control male sporogenesis. Plant Cell 2005, 17:3337-3349.

24. Li J, Wen J, Lease KA, Doke JT, Tax FE, Walker JC: BAK1, an Arabidopsis LRR receptor-like protein kinase, interacts with BRI1 and modulates brassinosteroid signaling. Cell 2002, 110:213-222.

25. Nam KH, Li JM: BRI1/BAK1, a receptor kinase pair mediating brassinosteroid signaling. Cell 2002, 110:203-212.

26. Karlova R, Boeren S, Russinova E, Aker J, Vervoort J, de Vries S: The Arabidopsis SOMATIC EMBRYOGENESIS RECEPTOR-LIKE KINASE1 protein complex includes BRASSINOSTEROID-INSENSITIVE1. Plant Cell 2006, 18:626-638.

27. Kemmerling B, Schwedt A, Rodriguez P, Mazzotta S, Frank M, Qamar SA, Mengiste T, Betsuyaku S, Parker JE, Mussig C, et al: The BRI1-associated kinase 1, BAK1, has a brassinolide-independent role in plant cell-death control. Curr Biol 2007, 17:1116-1122.

28. Chinchilla D, Zipfel C, Robatzek S, Kemmerling B, Nurnberger T, Jones JDG, Felix G, Boller T: A flagellin-induced complex of the receptor FLS2 and BAK1 initiates plant defence. Nature 2007, 448:497-U412.

29. Heese A, Hann DR, Gimenez-Ibanez S, Jones AME, He K, Li J, Schroeder JI, Peck SC, Rathjen JP: The receptor-like kinase SERK3/BAK1 is a central regulator of innate immunity in plants. Proc Natl Acad Sci USA 2007, 104:12217-12222.

30. Hu H, Xiong $L$, Yang $Y$ : Rice SERK1 gene positively regulates somatic embryogenesis of cultured cell and host defense response against fungal infection. Planta 2005, 222:107-117.

31. Godiard L, Sauviac L, Torii K, Grenon O, Mangin B, Grimsley N, Marco Y: ERECTA, an LRR receptor-like kinase protein controlling development pleiotropically affects resistance to bacterial wilt. Plant J 2003, 36:353-365.

32. Schulze B, Mentzel T, Jehle AK, Mueller K, Beeler S, Boller T, Felix G, Chinchilla D: Rapid heteromerization and phosphorylation of 
ligand-activated plant transmembrane receptors and their associated kinase BAK1. J Biol Chem 2010, 285:9444-9451.

33. Russinova E, Borst J-W, Kwaaitaal M, Cano-Delgado A, Yin Y, Chory J, C de Vries S: Heterodimerization and endocytosis of Arabidopsis brassinosteroid receptors BRI1 and AtSERK3 (BAK1). Plant Cell 2004, 16:3216-3229.

34. Kwaaitaal M, de Vries SC, Russinova E: Arabidopsis thaliana Somatic Embryogenesis Receptor Kinase 1 protein is present in sporophytic and gametophytic cells and undergoes endocytosis. Protoplasma 2005, 226:55-65.

35. Nolan KE, Kurdyukov S, Rose RJ: Expression of the SOMATIC EMBRYOGENESIS RECEPTOR-LIKE KINASE1 (SERK1) gene is associated with developmental change in the life cycle of the model legume Medicago truncatula. J Exp Bot 2009, 60:1759-1771.

36. Sprent J: Legume Nodulation - A Global Perspective. Oxford: WileyBlackwell; 2009.

37. Hirst JD, Vieth M, Skolnick J, Brooks CL III: Predicting leucine zipper structures from sequence. Protein Eng 1996, 9:657-662.

38. Lavin M, Herendeen PS, Wojciechowski MF: Evolutionary rates analysis of Leguminosae implicates a rapid diversification of lineages during the Tertiary. Syst Biol 2005, 54:575-594.

39. Bertioli DJ, Moretzsohn MC, Madsen LH, Sandal N, Leal-Bertioli SCM, Guimaraes PM, Hougaard BK, Fredslund J, Schauser L, Nielsen AM, et al: An analysis of synteny of Arachis with Lotus and Medicago sheds new light on the structure, stability and evolution of legume genomes. BMC Genomics 2009, 10:45.

40. Sasaki G, Katoh K, Hirose N, Suga H, Kuma K-i, Miyata T, Su Z-H: Multiple receptor-like kinase cDNAs from liverwort Marchantia polymorpha and two charophycean green algae, Closterium ehrenbergii and Nitella axillaris: Extensive gene duplications and gene shufflings in the early evolution of streptophytes. Gene 2007, 401:135-144.

41. Schmutz J, Cannon SB, Schlueter J, Ma JX, Mitros T, Nelson W, Hyten DL, Song QJ, Thelen JJ, Cheng JL, et al: Genome sequence of the palaeopolyploid soybean. Nature 2010, 463:178-183.

42. Cannon SB, May GD, Jackson SA: Three sequenced legume genomes and many crop species: Rich opportunities for translational genomics. Plant Physiol 2009, 151:970-977.

43. Song DH, Li GJ, Song FM, Zheng Z: Molecular characterization and expression analysis of OSBISERK1, a gene encoding a leucine-rich repeat receptor-like kinase, during disease resistance responses in rice. $\mathrm{Mol}$ Biol Rep 2008, 35:275-283.

44. Albertini E, Marconi G, Reale L, Barcaccia G, Porceddu A, Ferranti F, Falcinelli M: SERK and APOSTART. Candidate genes for apomixis in Poa pratensis. Plant Physiol 2005, 138:2185-2199.

45. Nolan KE, Rose RJ, Gorst JE: Regeneration of Medicago truncatula from tissue culture: increased somatic embryogenesis from regenerated plants. Plant Cell Rep 1989, 8:278-281.

46. Hoffmann B, Trinh TH, Leung J, Kondorosi A, Kondorosi E: A new Medicago truncatula line with superior in vitro regeneration, transformation, and symbiotic properties isolated through cell culture selection. Mol PlantMicrobe Interact 1997, 10:307-315.

47. Rose RJ, Nolan KE, Bicego L: The development of the highly regenerable seed line Jemalong $2 \mathrm{HA}$ for transformation of Medicago truncatula Implications for regenerability via somatic embryogenesis. J Plant Physiol 1999, 155:788-791.

48. Araujo SD, Duque A, dos Santos D, Fevereiro MPS: An efficient transformation method to regenerate a high number of transgenic plants using a new embryogenic line of Medicago truncatula cv. Jemalong. Plant Cell Tissue Organ Cult 2004, 78:123-131.

49. Wang $B B$, Brendel V: Genomewide comparative analysis of alternative splicing in plants. Proc Natl Acad Sci USA 2006, 103:7175-7180.

50. Wang BB, O'Toole M, Brendel V, Young ND: Cross-species EST alignments reveal novel and conserved alternative splicing events in legumes. $B M C$ Plant Biol 2008, 8:17.

51. Gou XP, He K, Yang H, Yuan T, Lin HH, Clouse SD, Li J: Genome-wide cloning and sequence analysis of leucine-rich repeat receptor-like protein kinase genes in Arabidopsis thaliana. BMC Genomics 2010, 11:19.

52. Ner-Gaon H, Halachmi R, Savaldi-Goldstein S, Rubin E, Ophir R, Fluhr R: Intron retention is a major phenomenon in alternative splicing in Arabidopsis. Plant J 2004, 39:877-885.
53. Jeong S, Trotochaud AE, Clark SE: The Arabidopsis CLAVATA2 gene encodes a receptor-like protein required for the stability of the CLAVATA1 receptor-like kinase. Plant Cell 1999, 11:1925-1933.

54. Jordan T, Schornack S, Lahaye T: Alternative splicing of transcripts encoding Toll-like plant resistance proteins - what's the functional relevance to innate immunity? Trends Plant Sci 2002, 7:392-398.

55. Zhang XC, Gassmann W: RPS4-Mediated disease resistance requires the combined presence of RPS4 transcripts with full-length and truncated open reading frames. Plant Cell 2003, 15:2333-2342.

56. Wells CA, Chalk AM, Forrest A, Taylor D, Waddell N, Schroder K, Himes SR, Faulkner G, Lo S, Kasukawa T, et al: Alternate transcription of the Toll-like receptor signaling cascade. Genome Biol 2006, 7:17.

57. Tang $P$, Zhang $Y$, Sun $X$, Tian D, Yang S, Ding J: Disease resistance signature of the leucine-rich repeat receptor-like kinase genes in four plant species. Plant Sci 2010, 179:399-406.

58. de Castro E, Sigrist CJA, Gattiker A, Bulliard V, Langendijk-Genevaux PS, Gasteiger E, Bairoch A, Hulo N: ScanProsite: detection of PROSITE signature matches and ProRule-associated functional and structural residues in proteins. Nucleic Acids Res 2006, 34:W362-W365.

59. Bendtsen JD, Nielsen H, von Heijne G, Brunak S: Improved prediction of signal peptides: SignalP 3.0. J Mol Biol 2004, 340:783-795.

60. Bendtsen JD, Jensen $\sqcup$, Blom N, von Heijne G, Brunak S: Feature-based prediction of non-classical and leaderless protein secretion. Protein Eng Des Sel 2004, 17:349-356.

61. Krogh A, Larsson B, von Heijne G, Sonnhammer ELL: Predicting transmembrane protein topology with a hidden Markov model: Application to complete genomes. J Mol Biol 2001, 305:567-580

62. Gasteiger E, Hoogland C, Gattiker A, Duvaud S, Wilkins MR, Appel RD, Bairoch A: Protein identification and analysis tools on the ExPASy server. In The Proteomics Protocols Handbook. Edited by: Walker JM. Totowa NJ, USA: Humana Press; 2005:571-607.

63. Larkin MA, Blackshields G, Brown NP, Chenna R, McGettigan PA, McWilliam H, Valentin F, Wallace IM, Wilm A, Lopez R, et al: Clustal W and Clustal X version 2.0. Bioinformatics 2007, 23:2947-2948.

64. Needleman SB, Wunsch CD: A general method applicable to search for similarities in amino acid sequence of 2 proteins. J Mol Biol 1970, 48:443.

65. Gaut BS, Morton BR, McCaig BC, Clegg MT: Substitution rate comparisons between grasses and palms: Synonymous rate differences at the nuclear gene Adh parallel rate differences at the plastid gene rbcL. Proc Natl Acad Sci USA 1996, 93:10274-10279.

66. Ramakers C, Ruijter JM, Deprez RHL, Moorman AFM: Assumption-free analysis of quantitative real-time polymerase chain reaction (PCR) data. Neurosci Lett 2003, 339:62-66.

67. Pfaffl MW: A new mathematical model for relative quantification in realtime RT-PCR. Nucleic Acids Res 2001, 29:2002-2007.

68. Johnson LN, Noble MEM, Owen DJ: Active and inactive protein kinases: Structural basis for regulation. Cell 1996, 85:149-158.

69. Ito $Y$, Takaya $K$, Kurata N: Expression of SERK family receptor-like protein kinase genes in rice. Biochim Biophys Acta-Gene Struct Expression 2005, 1730:253-258.

70. Li D, Wang L, Wang M, Xu YY, Luo W, Liu YJ, Xu ZH, Li J, Chong K: Engineering OsBAK1 gene as a molecular tool to improve rice architecture for high yield. Plant Biotechnol J 2009, 7:791-806.

71. Santos MD, Romano E, Yotoko KSC, Tinoco MLP, Dias BBA, Aragao FJL: Characterisation of the cacao somatic embryogenesis receptor-like kinase (SERK) gene expressed during somatic embryogenesis. Plant Sci 2005, 168:723-729.

doi:10.1186/1471-2229-11-44

Cite this article as: Nolan et al:: Characterisation of the legume SERK-NIK gene superfamily including splice variants: Implications for development and defence. BMC Plant Biology 2011 11:44. 